\title{
Formation of 4-hydroxybenzoate in Escherichia coli: characterization of the ubic gene and its encoded enzyme chorismate pyruvate-lyase
}

\author{
Marion Siebert, Klaus Severin and Lutz Heide \\ Author for correspondence: Lutz Heide: Tel: +49761 2032804. Fax: +497612032803. \\ e-mail:melzer@sun1.ruf.uni-freiburg.de
}

Institut für Pharmazeutische Biologie, Universităt Freiburg, Schänzlestr. 1, 79104 Freiburg, Germany

\begin{abstract}
Chorismate pyruvate-lyase from Escherichia coli converts chorismate to 4-hydroxybenzoate. The enzyme was enriched 3000-fold by overexpression and chromatographic purification. It has an apparent $K_{m}$ value for chorismate of 6.1 $\mu \mathrm{M}$ and an isoelectric point of pH 6.45. The enzyme activity did not require metal cofactors. Promoter sequences in the $5^{\prime}$ flanking sequences of the ubiCA operon were localized by transcription and translation of active chorismate pyruvate-lyase in vitro from different PCR fragments. Sequencing of the ubic gene of the mutant strain AN244 revealed a G $\rightarrow$ A transition resulting in a change from glutamic acid to lysine. A feeding experiment with [1,7${ }^{13} \mathrm{C}_{2}$ ]shikimate confirmed the chorismate pyruvate-lyase as the sole enzymic source of 4-hydroxybenzoate in vivo.
\end{abstract}

Keywords: ubiquinone, chorismate, 4-hydroxybenzoate, chorismate pyruvate-lyase, Escherichia coli

\section{INTRODUCTION}

4-Hydroxybenzoate (PHB) is a key intermediate in the biosynthesis of ubiquinones in all living organisms. It is formed in plants and animals from chorismate via phenylpropanoid intermediates (see Fig. 1) (Pennock \& Threlfall, 1983). In bacteria, the contribution of this pathway to the biosynthesis of PHB is not clearly established. The apparent incorporation of [U${ }^{14} \mathrm{Cl}$ tyrosine into ubiquinone, observed in Rhodospirillum rubrum, was largely, but not entirely due to contamination of the labelled tyrosine with labelled 4-hydroxybenzaldehyde (Parson \& Rudney, 1965). Conversion of tyrosine to PHB was observed in cell-free enzyme extracts from Aerobacter aerogenes (Klebsiella pneumoniae), but not from Escherichia coli (Cox \& Gibson, 1966). On the other hand, a direct conversion of chorismate to PHB was observed in crude E. coli extracts, and a mutant unable to carry out this reaction was isolated (Gibson \& Gibson, 1964; Lawrence et al., 1974). This led to the proposal that PHB is produced by a one-step reaction catalysed by the enzyme chorismate pyruvate-lyase (CPL), the translation product of the gene $u b i C$ (see Fig. 1).

Recently, this hypothesis has been confirmed by the cloning of $u b i C$ and the purification of CPL, independently

Abbreviations: PHB, 4-hydroxybenzoate; CPL, chorismate pyruvate-lyase; $\mathrm{Et}_{2} \mathrm{O}$, diethyl ether. by Nichols \& Green (1992) and by our laboratory (Siebert et al., 1992). The ubiC gene is situated in an operon structure together with $u b i A$; the latter gene encodes the enzyme $\mathrm{PHB}$ polyprenyltransferase, the subsequent enzymic step in ubiquinone biosynthesis. Although CPL has been purified to homogeneity (Nichols \& Green, 1992 ) as a monomeric polypeptide of approximately $19 \mathrm{kDa}$, the only biochemical data reported up to now are the $K_{\mathrm{m}}$ value for chorismate, determined as $9 \cdot 7 \mu \mathrm{M}$, and the turnover number, calculated as $49 \mathrm{~min}^{-1}$.

In this study, we present further biochemical characterization of CPL and confirm the role of the CPL reaction as the sole source of $\mathrm{PHB}$ in vivo. In vitro transcription/ translation experiments with $\mathrm{UbiC}$ gave evidence for the localization of the promoter region. Furthermore, we have sequenced the mutated $u b i C$ gene of $E$. coli AN244 and we discuss the role of the affected amino acid residue in the reaction mechanism.

\section{METHODS}

Chemicals and enzymes. Chorismate was purchased as the barium salt from Sigma. $\left[{ }^{35} \mathrm{~S}\right] \mathrm{dATP} \alpha \mathrm{S}$ and $\left[{ }^{35} \mathrm{~S}\right]$ methionine were from Amersham. Taq polymerase was obtained from Promega or Pharmacia. PCR primers were synthesized by MWG Biotech.

Bacteria, media, plasmids, and DNA manipulation. E. coli AN244, AN92, AN385 and SG13009 are described by Lawrence et al. (1974), Young et al. (1971), Wallace \& Young (1977), and 


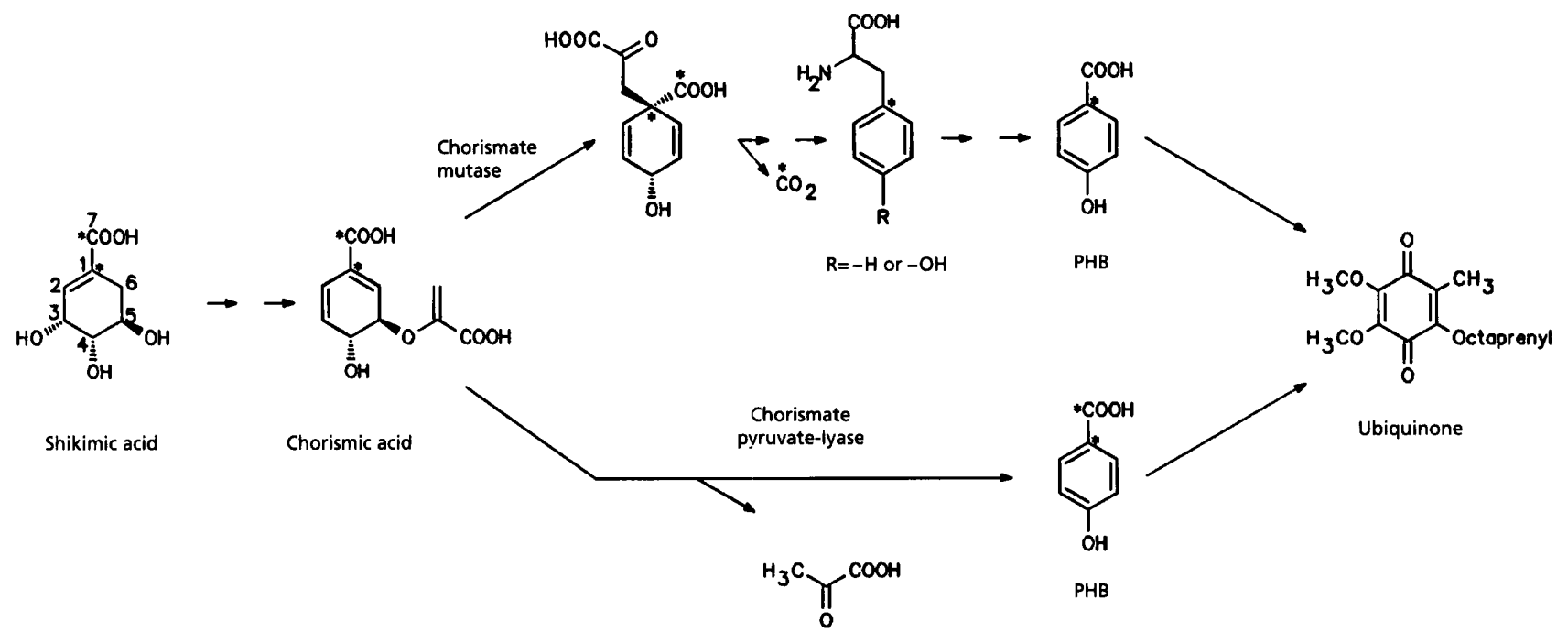

Fig. 1. Biosynthesis of ubiquinone: (a) in plants and animals (upper pathway) and (b) in bacteria (lower pathway).

Gottesman et al. (1981), respectively. pBluescriptIIKS + (Short et al., 1988) and E. coli XL1Blue were obtained from Stratagene, pTZ19R and pUC18 from Pharmacia, and pREP4 from Qiagen. pALMU1 is described by Siebert et al. (1992); pALMU3 contains a $1.86 \mathrm{~kb}$ SacI fragment from the pALMU1 insert, ligated into the SacI site of pTZ19R. pUBIC contains the PCRamplified $u b i C$ gene (primer ubiC-3F and ubiC-R, see below) which was treated with Klenow polymerase and $\mathrm{T} 4$ kinase prior to ligation (Sure Ligation Kit, Pharmacia) into the $S \mathrm{maI}$ site of pUC18. The accuracy of the amplification was confirmed by sequencing. Sequencing reactions were done using the USB Sequencing Kit in accordance with the manufacturer's instructions. Cultivation of bacteria, cloning and DNA manipulation were carried out according to standard procedures (Sambrook $e t$ al., 1989). DNA and protein sequence analysis were performed using the HUSAR program package at the DKFZ Heidelberg, FRG.

Assays for enzyme activity. Commercially available barium chorismate contains, besides other impurities, a considerable amount of PHB. Therefore it had to be purified for the enzyme assay using the following procedure. Six milligrams of barium chorismate dissolved in $100 \mu \mathrm{l}$ sodium acetate buffer $(0.75 \mathrm{M}$, $\mathrm{pH} 4 \cdot 0$ ) were extracted twice with $1 \mathrm{ml} \mathrm{Et}_{2} \mathrm{O}$. The organic layer was discarded, and the aqueous phase adjusted to $\mathrm{pH} 8.0$ with Tris buffer $(0.5 \mathrm{M}, \mathrm{pH} 8.0)$ and $0.1 \mathrm{M} \mathrm{NaOH}$. Unless stated otherwise, the assay for CPL activity was carried out according to Siebert et al. (1992) with an incubation time of $8 \mathrm{~min}$ and $50 \mu \mathrm{M}$ chorismate. PHB was extracted from the reaction mixture and assayed by HPLC, using 3-hydroxybenzoic acid as an internal standard. Values for enzymic PHB formation are corrected taking into account the PHB formed by chemical decomposition of chorismate during incubation. The reaction was linear with time for $15 \mathrm{~min}$ and with protein concentration between 30 and $300 \mu \mathrm{g}$ crude protein preparation $\mathrm{ml}^{-1}$. For the determination of the $K_{\mathrm{m}}$ value, incubations were carried out for $3 \mathrm{~min}$ at $37^{\circ} \mathrm{C}$, with $1.4 \mu \mathrm{g}$ purified enzyme (see below) and chorismate concentrations between $2 \cdot 1$ and $33.8 \mu \mathrm{M}$. Isochorismate was tested as a substrate at a concentration of $47 \mu \mathrm{M}$, with detection of salicylic acid formation by HPLC. For the investigation of the inhibitory effect of PHB, a coupled photometric assay was used; in this case, the incubation mixture contained, in a total volume of $1 \mathrm{ml}, 50 \mu \mathrm{mol}$ Tris $/ \mathrm{HCl} \mathrm{pH} \mathrm{8.0,}$ $200 \mu \mathrm{mol} \mathrm{NaCl}, 500 \mathrm{nmol}$ chorismate, $1.4 \mu \mathrm{g}$ purified enzyme, $5.5 \mathrm{U}$ lactate dehydrogenase, and $100 \mathrm{nmol} \mathrm{NADH}$. The decrease in absorbance was monitored at $340 \mathrm{~nm}$. Induction experiments were carried out by adding IPTG to a final concentration of $1 \mathrm{mM}$ to the bacterial culture at an $\mathrm{OD}_{600}$ of about $0 \cdot 7$.

Enzyme purification. This was carried out according to Siebert et al. (1992), using Sephadex G-75 for the gel chromatographic purification step.

PCR and in vitro transcription and translation. Primers used for PCR were: ubiC-1F, 5'-TTCAGCTCCAAATCTCA-3'; ubiC-2F, 5'-GTTGCGTTTTTGTTGCG-3'; ubiC-3F, 5' TGTAACGGAGAGT'TCGG-3' ; ubiC-R, 5' -ATTCTGCGTCAGACTCC-3'. A schematic view of their locations is given in Fig. 2. PCR was performed with minor modifications to the method of Lesley et al. (1991) in $100 \mu \mathrm{l}$ final volume with $20 \mathrm{ng}$ pALMU1 as template, 50 pmol of each primer, $0 \cdot 1 \mathrm{mM}$ of each dNTP, and $1 \mathrm{U}$ Taq polymerase. Reactions were started by 5 min denaturation at $95^{\circ} \mathrm{C}$, followed by 35 cycles of $1 \mathrm{~min}$ annealing at $52^{\circ} \mathrm{C}, 3 \mathrm{~min}$ chain elongation at $72{ }^{\circ} \mathrm{C}$, and $1 \mathrm{~min}$ denaturation at $95{ }^{\circ} \mathrm{C}$. The reaction was finished after a final elongation step of $10 \mathrm{~min}$ at $72{ }^{\circ} \mathrm{C}$, followed by extraction with phenol. Excess primers were removed by chromatography on Sephadex G-50 and ethanol precipitation. Redissolved DNA fragments were analysed by gel electrophoresis and their concentration estimated by comparison with a standard of known concentration.

In vitro transcription and translation was done using the S-30 extract for linear DNA from Promega essentially as described by Lesley et al. (1991) and in the manufacturer's instructions. For visualization of protein bands the extract was incubated with approximately $2 \mu \mathrm{g}$ DNA (plasmid or PCR fragments) including $\left[{ }^{35} \mathrm{~S}\right]$ methionine for $2 \mathrm{~h}$ at $37^{\circ} \mathrm{C}$. Translation products were precipitated with acetone, redissolved in SDS loading buffer and separated on a $12 \%(\mathrm{w} / \mathrm{v})$ polyacrylamide gel (Laemmli, 1970). The gel was dried and exposed to Kodak X-Omat AR film. For measurement of enzyme activity, $2 \mu \mathrm{g}$ supercoiled plasmid DNA or $4 \mu \mathrm{g}$ PCR fragments were included in a non-radioactive transcription/translation assay $\left(2 \mathrm{~h}\right.$ at $\left.37^{\circ} \mathrm{C}\right)$. After addition of 
(a)

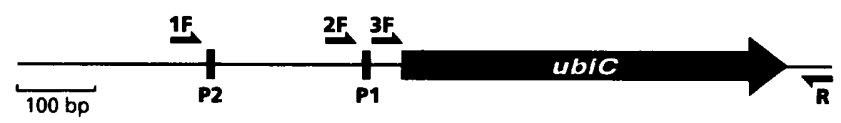

(b)

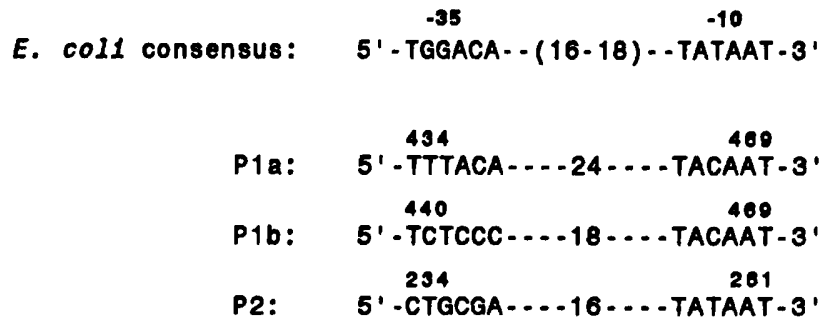

Fig. 2. Localization of the potential promoter regions. (a) Schematic overview of the ubic sequence, which is available in the EMBL data library (accession number X66619) and its flanking regions. The locations of the putative promoter structures are marked $P 1$ and $P 2$. Primers used for the in vitro transcription/translation experiment: $1 \mathrm{~F}$, ubiC-1F; $2 \mathrm{~F}$, ubiC-2F; $3 F$, ubiC-3F; $R$, ubiC-R (the lengths of the arrows indicating the primer locations are not to scale). (b) Sequence comparison of the $E$. coli consensus and the putative ubiCA promoters. Numbering refers to the original sequence published by Siebert et al. (1992).

$10 \%(\mathrm{v} / \mathrm{v})$ glycerol, the reaction mixtures could be stored at $-20^{\circ} \mathrm{C}$ or were used directly for the enzyme assay.

Generation of single-stranded DNA by PCR. Generation of single-stranded DNA was performed in two steps. First, $1 \mu \mathrm{g}$ genomic DNA, extracted from E. coli AN244 by a standard procedure (Sambrook et al., 1989), was used for the symmetrical amplification using the protocol described above with the primers ubiC-2F and ubiC-R and $2 \mathrm{U}$ Taq polymerase. Then the asymmetrical PCR reaction was performed with $1 \mu \mathrm{l}$ of the first reaction mixture (containing approximately $50 \mathrm{ng}$ doublestranded DNA) and 1 and 50 pmol of the respective primers. The amplified DNA was purified of Taq polymerase, excess primers and dNTPs by microconcentration (Microcon 100, Amicon).

Direct sequencing of PCR-amplified DNA. Ten picomoles $(1 \mu \mathrm{l})$ of the limiting primer of the asymmetrical PCR reaction (ubiC$2 \mathrm{~F}$, ubiC-3F, or ubiC-R) were annealed to about $100 \mathrm{ng}$ singlestranded DNA (in $9 \mu \mathrm{l} 1 \times$ sequencing buffer) by warming the sample to $65^{\circ} \mathrm{C}$ for $2 \mathrm{~min}$ and cooling over a period of $30 \mathrm{~min}$ to room temperature. The sequencing reactions were performed using the USB kit according to the manufacturer's instructions with minor changes in labelling time $(3 \mathrm{~min})$ and buffer composition $\left(\mathrm{Mn}^{2+}\right.$ instead of $\left.\mathrm{Mg}^{2+}\right)$.

Feeding of $\left[1,7-{ }^{13} \mathrm{C}_{2}\right]$ shikimic acid. To 10 flasks each containing $1 \mathrm{l}$ of a minimal medium with $10 \mathrm{mM}$ citrate and $30 \mathrm{mM}$ glucose (Wallace \& Young, 1977; Stroobant et al., 1972), a total of $1 \mathrm{mmol}(176.3 \mathrm{mg})\left[1,7-{ }^{13} \mathrm{C}_{2}\right]$ shikimic acid (Cho et al., 1992) was added, and the flasks were each inoculated with $50 \mathrm{ml}$ of a preculture (overnight) of E. coli AN385 in the same medium.

After shaking for $11 \mathrm{~h}$ at $37^{\circ} \mathrm{C}$ and 60 strokes $\min ^{-1}$ (reciprocal shaker, $100 \mathrm{~mm}$ stroke), cells were centrifuged off $(5000 \mathrm{~g})$ and discarded. The medium was adjusted to $\mathrm{pH} 1$ with $\mathrm{HCl}$ and extracted with 3 l ethyl acetate. The organic layer was extracted with $500 \mathrm{ml}$ of aqueous $\mathrm{NaHCO}_{3}(1 \mathrm{M})$. The $\mathrm{NaHCO}_{3}$ layer was acidified $(\mathrm{HCl})$ and extracted with $3 \times 500 \mathrm{ml} \mathrm{Et}_{2} \mathrm{O}$. The combined $\mathrm{Et}_{2} \mathrm{O}$ layers were dried $\left(\mathrm{NaSO}_{4}\right)$ and evaporated to dryness. The residue was subjected to preparative TLC $\left(\mathrm{SiO}_{2}\right.$; solvent: $\mathrm{n}$-hexane/ethyl acetate/methanol/formic acid, $70: 28: 1: 1$, by vol. $)$. The spot of $\mathrm{PHB}\left(R_{F} 0 \cdot 23\right)$ was scraped off, eluted with methanol and subjected to reverse-phase column chromatography (Lobar RP-8; solvent: methanol/water, 1:1, $\mathrm{v} / \mathrm{v}$ ). Fractions containing PHB were combined and evaporated, and PHB was crystallized from water $(75 \mu \mathrm{l})$ with a yield of $4.89 \mathrm{mg}$.

\section{RESULTS \\ Overexpression of $\mathrm{CPL}$}

In cell-free extracts of wild-type E. coli strains, chorismate is predominantly metabolized to prephenate by the chorismate mutase reaction (Lawrence et al., 1974), preventing the detection of CPL activity (data not shown). We therefore used the E. coli mutant AN92, which is blocked in chorismate mutase as well as in anthranilate synthase (Young et al., 1971), for detection of CPL activity in crude extracts.

Overexpression of CPL was achieved by transformation of strain AN92 with plasmids pALMU1, pALMU3 or pUBIC. pALMU1 and pALMU3 both contain the entire ubiC $A$ operon with its $5^{\prime}$ flanking sequences, pALMU1 in the vector pBluescriptKSII +, pALMU3 in the vector pTZ19R (see Methods).

Transformation of strain AN92 with pALMU1 or pALMU3 resulted in an approximately 38 -fold increase of CPL activity in crude enzyme extracts, compared to the activity of AN92 transformed with the empty vectors. CPL activity could not be stimulated by the addition of IPTG to the culture medium. This indicates that in both vectors the gene is under control of its own promoter rather than under the lac $Z$ promoter of the vector. This assumption is also supported by the expression of the UbiC protein in E. coli minicells from pTZ19R vectors, containing the pALMU3 insert in either orientation (Siebert et al., 1992) and by the in vitro transcription/translation experiments described below.

Plasmid pUBIC contains only the $u b i C$ structural gene, obtained by PCR amplification and ligated into the vector pUC18 (see Methods). From this recombinant plasmid, UbiC is synthesized as a LacZ fusion protein under the control of the lac $Z$ promoter. By transformation of strain AN92 with this plasmid, a 1400-fold overexpression of CPL activity was achieved. Since strain AN92 contains only low amounts of lac repressor, no IPTG induction of enzyme activity was observed. However, in strain SG13009/pREP4, which overproduces the Lac repressor protein, CPL activity was, upon transformation with pUBIC, inducible by IPTG as expected. Strains containing these overexpression vectors showed detectable CPL activity even in the presence of intact chorismate mutase. 
Table 1. Effects of ions on CPL activity

Enzyme activity was determined as described in Methods.

\begin{tabular}{|lcc|}
\hline Addition & \multicolumn{2}{c|}{ PHB formation } \\
\cline { 2 - 3 } & pmol & $\begin{array}{c}\text { Percentage } \\
\text { of control }\end{array}$ \\
\hline None & & 100 \\
$\mathrm{MgCl}_{2}(1 \mathrm{mM})$ & 823 & 106 \\
$\mathrm{MgCl}_{2}(10 \mathrm{mM})$ & 871 & 160 \\
$\mathrm{EDTA}(2.5 \mathrm{mM})$ & 1318 & 119 \\
$\mathrm{EDTA}(25 \mathrm{mM})$ & 980 & 156 \\
$\mathrm{NaCl}(200 \mathrm{mM})$ & 1280 & 151 \\
$\mathrm{NaCl}(600 \mathrm{mM})$ & 1239 & 92 \\
$\mathrm{Tris} / \mathrm{HCl}(410 \mathrm{mM})$ & 758 & 128 \\
\hline
\end{tabular}

\section{Properties of CPL}

From strain XL1Blue, transformed with pALMU1, CPL was purified 87 -fold as described previously (Siebert et al., 1992). Considering the 38-fold overexpression of CPL in XL1Blue harbouring pALMU1, an approximately 3000fold enrichment was achieved, compared with extracts from wild-type strains. In the presence of $10 \%$ glycerol, the purified enzyme could be stored at $-20{ }^{\circ} \mathrm{C}$ for several months without significant loss of activity.

The enzymic reaction was not dependent on metal cofactors (Table 1). The observed stimulation of the activity by $10 \mathrm{mM} \mathrm{MgCl}_{2}$ was apparently an effect of ionic strength, since a similar stimulation could be achieved by EDTA, $\mathrm{NaCl}$ or Tris/ $\mathrm{HCl}$. The addition of $160-200 \mathrm{mM}$ $\mathrm{NaCl}$ to the reaction buffer $(50 \mathrm{mM}$ Tris/ $\mathrm{HCl})$ increased the activity by $50 \%$. In the absence of $\mathrm{NaCl}$, the optimal concentration of Tris/ $\mathrm{HCl}$ was $200-400 \mathrm{mM}$.

A strong product inhibition was observed in the presence of PHB. Using a chorismate concentration of $500 \mu \mathrm{M}$, the addition of $25 \mu \mathrm{M}$ or $100 \mu \mathrm{M}$ PHB reduced the reaction velocity by 51 or $83 \%$, respectively. Addition of an excess of chorismate reversed the inhibition, suggesting a competitive mechanism. In contrast, pyruvate did not show an inhibitory effect at concentrations up to $50 \mathrm{mM}$, using the HPLC assay for the measurement of enzyme activity.

Using a buffer containing citrate, borate and phosphate, each at $40 \mathrm{mM}$, the $\mathrm{pH}$ optimum of the CPL reaction was determined as $7 \cdot 5$, with half-maximal reaction velocities at pH 5.7 and $9 \cdot 2$. The enzyme showed an isoelectric point of pH 6.45, determined by the method of Harzer (1970), contrasting with the value of 8.08 calculated from the amino acid sequence using the HUSAR program.

The apparent $K_{\mathrm{m}}$ value for chorismate was calculated as $6.1 \mu \mathrm{M}$ with a standard deviation of $12 \%$, using the PENNZYME program (Eisenthal \& Cornish-Bowden, 1974; Cornish-Bowden \& Eisenthal, 1974; Cornish-Bowden, 1977). For these experiments, the incubation was shortened to $3 \mathrm{~min}$ in order to measure accurately the initial reaction velocities and to minimize productinhibition effects. When chorismate was replaced with $47 \mu \mathrm{M}$ isochorismate (Young et al., 1969) as substrate, no formation of salicylic acid could be detected, showing this pyruvate-lyase reaction to be specific for chorismate.

As expected, a reverse reaction could not be observed, using PHB concentrations up to $25 \mathrm{mM}$ and pyruvate concentrations up to $250 \mathrm{mM}$.

\section{Localization of the promoter region}

In vitro transcription/translation experiments from supercoiled as well as from PstI-linearized pALMU3 yielded a prominent protein band of $19 \mathrm{kDa}$ (Fig. 3). Because in the latter case the plasmid $l a c Z$ promoter is dissected from the ubiC gene, ubiC must be expressed from its own promoter.

As reported previously (Siebert et al., 1992), sequence analysis revealed two possible promoter regions for the ubiCA operon (see Fig. 2). The putative upstream promoter, designated P2, shows a perfect -10 box but weak homology to the -35 consensus sequence. The potential downstream promoter, designated $\mathrm{P} 1 \mathrm{a}$, has wellconserved -35 and -10 boxes which are, however, separated by an unprecedentedly long spacing of $24 \mathrm{bp}$.

To examine the localization of sequences with promoter activity, we undertook in vitro transcription/translation experiments with PCR-amplified DNA fragments containing different portions of the $u b i C$ upstream region. Radioactive labelling detected no translation products from a DNA fragment lacking both putative promoters (using the $5^{\prime}$ primer ubiC-3F). In contrast, the region of $104 \mathrm{bp}$ upstream of the start codon (obtained with the primer ubiC-2F) containing only the $\mathrm{P} 1$ region is sufficient for protein expression (Fig. 3).

The above results were confirmed by measurement of the enzyme activity of the CPL formed by in vitro transcription/translation. S-30 extracts incubated with the empty vector pTZ19R or the promoterless gene $u b i C$ (obtained with the primer ubiC-3F) showed little CPL activity : $0 \cdot 16 \pm 0.06$ and $0 \cdot 29 \pm 0.04 \mathrm{nmol} \mathrm{PHB} \mathrm{min}{ }^{-1}(\mathrm{mg}$ protein) ${ }^{-1}$, respectively (means $\pm \mathrm{SD}, n=4$ ). This residual activity might have been attributable to endogenous CPL present in the S-30 extracts. Presence of the putative promoter region $\mathrm{P} 1$ in the $u b i C$ fragment (obtained with the primer ubiC-2F) clearly enhanced this activity, to $0.68 \pm 0.11 \mathrm{nmol} \mathrm{min}^{-1} \mathrm{mg}^{-1}$. The activity was further increased by more than $50 \%$, to $1.06 \pm 0.15 \mathrm{nmol} \mathrm{min}-1$ $\mathrm{mg}^{-1}$, when additionally the upstream region containing the potential promoter $\mathrm{P} 2$ was present, using the DNA fragment generated with primer ubiC-1F. The activity obtained with pALMU3, which contains the entire $u b i C A$ operon in PTZ19R, was $1 \cdot 12 \pm 0 \cdot 22 \mathrm{nmol} \mathrm{min}{ }^{-1} \mathrm{mg}^{-1}$.

\section{Mutation of the ubiC gene in E. coli AN244}

E. coli AN244 carrying the ubiC437 mutant allele (Lawrence et al., 1974) is unable to convert chorismate into PHB. This mutant strain was originally obtained using $\quad N$-methyl- $N^{\prime}$-nitro- $N$-nitrosoguanidine as mutagen. 


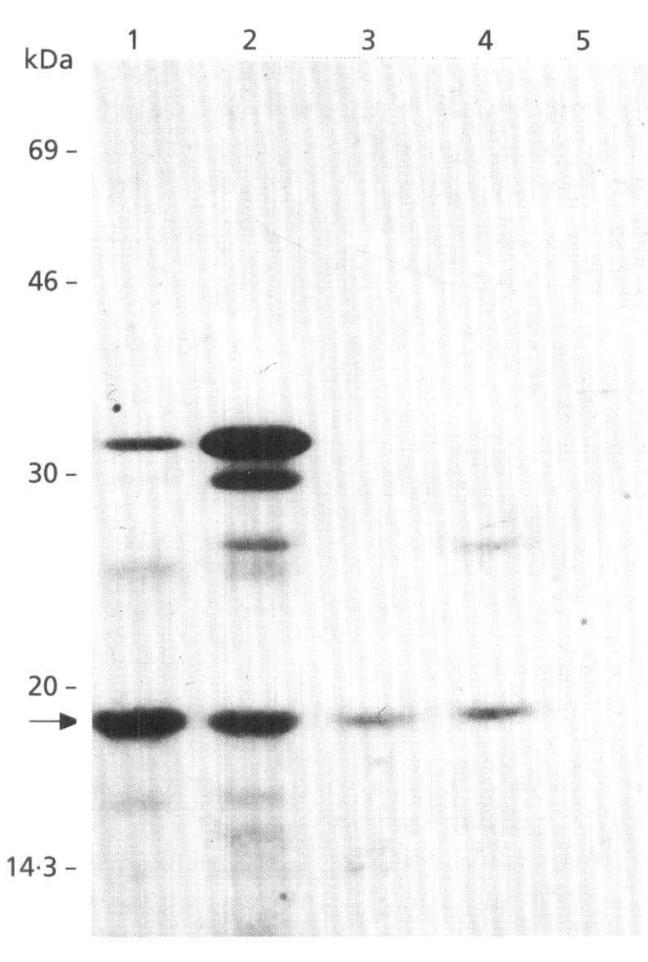

Fig. 3. In vitro translation products of plasmids and PCR fragments containing the ubic gene. In vitro expression and gel electrophoresis was carried out as described in Methods. Lanes 1 and 2, expression from PALMU3 in supercoiled or Pst/restricted form, respectively. Lanes 3 to 5 , translation products from PCR fragments generated with the $3^{\prime}$ primer ubiC-R and the $5^{\prime}$ primers ubiC-1F, ubiC-2F, and ubiC-3F, respectively. The arrow indicates the band formed by the ubiC gene product.

We analysed the entire $u b i C$ gene of AN244 by PCR direct sequencing. The only change detected within the gene in comparison with the wild-type was a point mutation located at position 466 near the carboxy-terminus of the gene. It shows a transition from $G$ to A (Fig. 4), which leads to a change of amino acid from glutamic acid (GAA) to lysine (AAA). Since direct PCR sequencing was employed, rather than sequencing of a cloned PCR fragment, the nucleotide change cannot be attributed to a PCR artifact.

\section{Feeding experiment with $\left[1,7^{13} C_{2}\right]$ shikimate}

The two possible biosynthetic pathways to PHB, i.e. via phenylpropanoid compounds or via the CPL reaction, differ in the fate of the carboxyl group of shikimate (Fig. $1):$ it is lost in the aromatization of prephenate on the route via phenylpropanoids, but gives rise to the carboxyl group of PHB in the CPL reaction. The relative contribution of the two pathways to the formation of PHB can be assessed by using as a precursor a shikimate sample carrying an isotope label in the carboxyl group and a reference label in the ring.

We have synthesized a double-labelled shikimic acid, carrying two ${ }^{13} \mathrm{C}$ atoms, one in the carboxyl group and one in the adjacent ring position (Cho et al., 1992). One

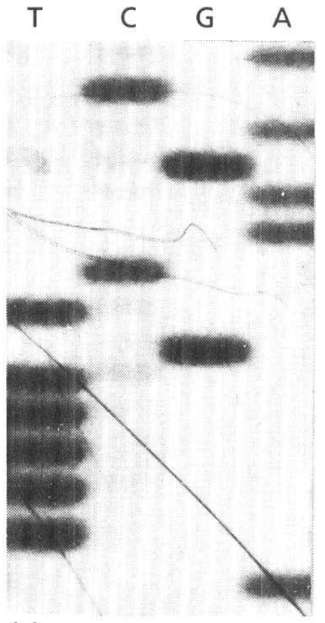

(a)

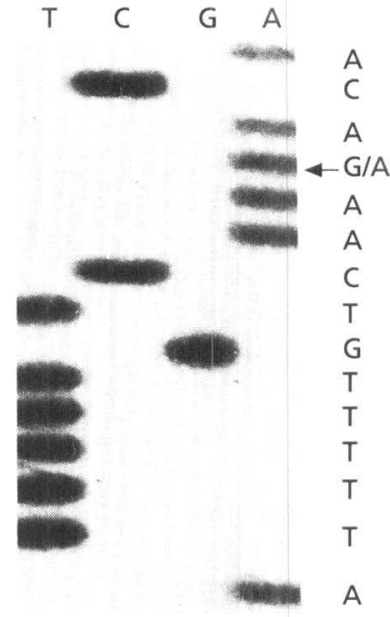

(b)
Fig. 4. Location of the mutation in the ubiC gene from E. coli AN244, which is blocked in the CPL reaction. The region from nucleotides 463 to 477 is shown (numbering refers to 1 as the translation start). (a) Wild-type sequence; (b) mutated sequence. The arrow indicates the exchange of the respective nucleotide. Amplification and sequencing reactions are described in Methods.

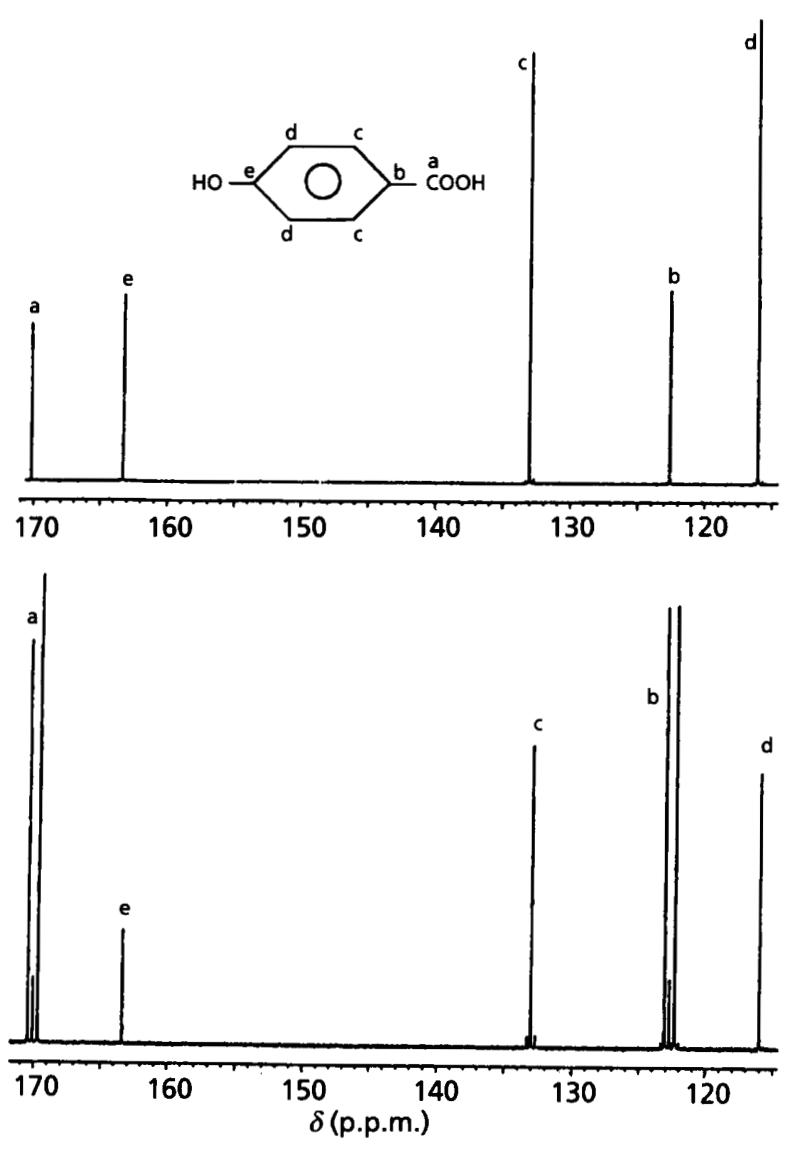

Fig. 5. ${ }^{13} \mathrm{C}-\mathrm{NMR}$ spectra of PHB: authentic PHB (upper panel), and PHB formed by $E$. coli AN385 after feeding of $[1,7-$ ${ }^{13} \mathrm{C}_{2}$ ]shikimate (lower panel). NMR: $100 \mathrm{MHz}$, inverse gated decoupling; $\mathrm{CD}_{3} \mathrm{OD},{ }^{13} \mathrm{C}$-depleted. 
millimole $(176.3 \mathrm{mg})$ of this compound was fed to the $E$. coli mutant AN385, which is unable to convert PHB into ubiquinone (Wallace \& Young, 1977) and therefore accumulates low amounts of PHB in the culture medium (Young et al., 1972); this PHB was extracted and purified (see Methods). In ${ }^{13} \mathrm{C}$ NMR analysis, each carbon of a molecule gives a signal due to the natural abundance of ${ }^{13} \mathrm{C}\left(1 \cdot 1 \%\right.$ of the predominant isotope $\left.{ }^{12} \mathrm{C}\right)$. Incorporation of isotope label from a ${ }^{13} \mathrm{C}$-labelled precursor results in increased signals of the respective carbon. If the precursor contains two ${ }^{13} \mathrm{C}$ atoms in adjacent positions, they give a doublet rather than a singlet signal, due to ${ }^{13} \mathrm{C}^{-13} \mathrm{C}$ coupling, i.e. due to either parallel or antiparallel spin of the neighbouring ${ }^{13} \mathrm{C}$. In ${ }^{13} \mathrm{C}$ NMR the PHB isolated from the feeding experiment showed coupled signals due to the incorporation of ${ }^{13} \mathrm{C}$ both into the carboxyl group (a) and into the neighbouring ring position (b) (Fig. 5, bottom). Incorporation of the shikimic acid with loss of the carboxyl group, in contrast, would have resulted in an increase of the singlet signal of the ring position (b) alone. Total incorporation was $14.8 \%$, and the detection limit for loss of C-7 was calculated as $1 \%$ of the total incorporation. Therefore, incorporation of shikimate into PHB proceeded with complete $(>99 \%)$ retention of the carboxyl group, i.e. exclusively via the CPL reaction.

\section{DISCUSSION}

CPL could be overexpressed 1400-fold in E. coli strains harbouring the plasmid pUBIC. The overexpressed enzyme is a fusion protein comprising the original CPL with 17 additional amino acids of the LacZ protein at its $\mathrm{N}$ terminus. Since these additional amino acids might influence the properties of the enzyme, we used for the characterization experiments the unmodified CPL, which could be obtained in approximately 3000 -fold enrichment by transformation of E. coli strains with plasmid pALMU1 and subsequent chromatographic purification.

The purified CPL did not accept isochorismate as substrate; this substance differs from chorismate by carrying the hydroxyl group in the 2-position instead of the 4-position. On the other hand, Nichols \& Green (1992) presented evidence which indicates that CPL can convert 4-amino-4-deoxychorismate to 4-aminobenzoate in vivo. Therefore a hydroxy or amino function in 4position appears to be essential for the reaction.

We determined the $K_{\mathrm{m}}$ value of CPL for chorismate as $6.1 \mu \mathrm{M}$, which is in reasonable agreement with the previously published value of $9.7 \mu \mathrm{M}$ (Nichols \& Green, 1992). The latter value was obtained with $30 \mathrm{~min}$ incubations, which in our hands proved to be beyond time-linearity of the reaction, probably due to the strong product inhibition by PHB which we have observed.

Some of the chorismate-metabolizing enzymes, i.e. isochorismate synthase (EntC), anthranilate synthase (TrpE subunit) and aminodeoxychorismate synthase (PabB subunit), show homologies to each other, especially at the carboxy-terminus of the proteins (Ozenberger et al., 1989), and all three enzymes require $\mathrm{Mg}^{2+}$ ions as cofactors. Walsh et al. (1990) have proposed that the role of the $\mathrm{Mg}^{2+}$ ion is to chelate the 4-hydroxy group of chorismate, making it a better leaving group. In contrast, the 4-hydroxy group is not removed from chorismate in the CPL and the chorismate mutase reactions. These two enzymes do not require $\mathrm{Mg}^{2+}$ ions and do not show homology to the other three chorismate-metabolizing enzymes nor to each other. As reported previously (Nichols \& Green, 1992), there is also no homology between UbiC and PabC, which catalyses the pyridoxal phosphate-dependent conversion of 4-amino-4-deoxychorismate to 4-aminobenzoate.

The $u b i C$ gene is, together with $u b i A$, part of a typical operon structure (Siebert et al., 1992). However, no sequence element with high homology to the E. coli consensus promoter and a conventional spacing of the -10 and -35 box could be detected within the $570 \mathrm{bp}$ directly upstream of the ATG start codon. Nevertheless, a region containing the $104 \mathrm{bp} 5^{\prime}$ of the start codon was sufficient to express the UbiC protein in vitro detected as radioactively labelled translation product and as active enzyme. This contrasts with the work of Nichols \& Green (1992), who found 169 bp of the upstream sequence not to be sufficient for generation of measurable enzyme activity, whereas 243 or more bp of this flanking region resulted in CPL formation. The difference may be caused by their method of expressing the enzyme in vivo using plasmids with a T7 promoter. The $104 \mathrm{bp}$ which we identified as sufficient for gene expression contain a -10 and a -35 box strongly homologous to the E. coli consensus promoter ( $\mathrm{P} 1 \mathrm{a}$ in Fig. 2) but their extremely long spacing of $24 \mathrm{bp}$ (compared to $17 \mathrm{bp}$ in average) has not been documented for functional $E$. coli promoters (Lisser \& Margalit, 1993). Because many promoters show only a rather weak homology to the consensus (Lisser \& Margalit, 1993), especially to the -35 box (O'Neill, 1989), we assume that the low-consensus -35 box depicted in Fig. 2 as P1b is the functional promoter element. However, exact localization of the promoter would require the determination of the transcription start site and mutational analysis of the putative promoter sequences. Usage of a longer fragment of $313 \mathrm{bp}$ of the region upstream of the ATG start codon increases the ubiC expression, probably due to the activity of an additional promoter element in this fragment as mentioned above.

Sequence analysis of the entire $u b i C$ gene, amplified from the $u b i C$ mutant $E$. coli AN244, revealed a point mutation causing a change of an amino acid residue from glutamate to lysine near the carboxy-terminus (position 156). The Chou-Fasman (Chou \& Fasman, 1978) and the GarnierOsguthorpe-Robson (Garnier et al., 1978) algorithms for the calculation of the secondary structure for the wildtype and the mutant $\mathrm{UbiC}$ yielded divergent results. While the former predicted a change from a helical structure (wild-type) to a $\beta$-sheet (mutant) in the affected region (amino acid residues 150 to 159), the latter showed no conformational difference. On the other hand, the change of glutamate to the positively charged lysine residue with the concomitant loss of enzyme activity may indicate that the negatively charged glutamate residue is essential for 

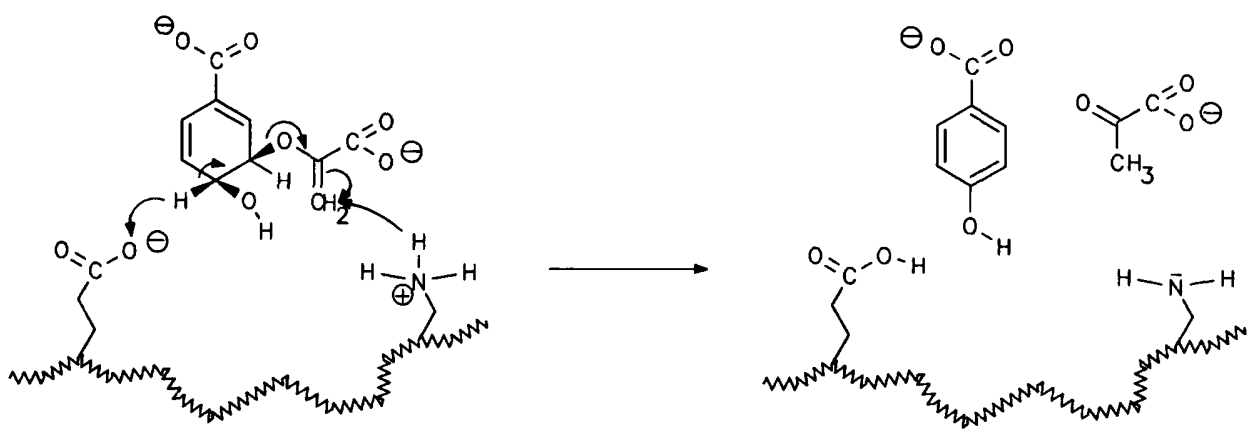

Fig. 6. Hypothetical reaction mechanism of the conversion of chorismate to PHB by CPL involving the glutamate residue.

the enzymic mechanism. Walsh et al. (1990) proposed a 1,2-elimination for the aromatization step in the CPL reaction starting with an initial abstraction of the $\mathrm{C}_{4}-\mathrm{H}$ of chorismate followed by the loss of the $\mathrm{C}_{3}$-enolpyruvyl group (see Fig. 6). For the first step a nucleophilic group is essential for acceptance of the proton. This group could be represented by glutamate but not by lysine. The proton needed for the pyruvate abstraction in the second step could be supplied by a basic residue, for example lysine or arginine. Both amino acids are located close to the site of the mutation. Further site-directed mutational analysis of this putative active site of the enzyme is required to confirm this assumption.

A major difficulty in the cloning of the $u b i C$ gene was the leaky phenotype of the $u b i C$ mutant strain AN244. Despite the mutation, ubiquinone is formed by this strain in an amount as high as $13 \%$ of the value obtained with external PHB supplementation (Lawrence et al., 1974). In the hands of Nichols \& Green (1992), this leakiness prevented the use of phenotypic complementation as a cloning strategy for $u b i C$. A possible explanation for this phenomenon could be that CPL is the major, but not the only, biosynthetic source of PHB, and that a pathway similar to the eukaryotic one, i.e. via phenylpropanoid intermediates (Fig. 1), can be used to some extent. Our feeding experiment with $\left[1,7-{ }^{13} \mathrm{C}_{2}\right]$ shikimate proved, however, that under the experimental conditions employed more than $99 \%$ of PHB is formed by the CPL reaction. Therefore, a phenylpropanoid pathway to $\mathrm{PHB}$ is not used to a significant extent. The leakiness of the phenotype may be due to a residual CPL activity of the mutated $U b i C$ gene product or, more likely, to the observed chemical decomposition of chorismate to $\mathrm{PHB}$ (Gibson \& Gibson, 1964; Siebert et al., 1992).

\section{ACKNOWLEDGEMENTS}

We are grateful to Dr I. G. Young (Canberra) for providing us with the E. coli AN244 and AN92 strains, to Dr G. Unden (Düsseldorf) for E. coli AN385, to K. Schmidt (Bonn) for a sample of isochorismic acid, and to Drs J. Schröder and G. Schröder for their help in the investigations of the $u b i C$ gene. Special thanks to Dr A. Bechthold for cloning of the $u b i C$ gene and helpful discussion and to Dr U. May for the development of the enzyme purification procedure. This work was supported by a Heisenberg scholarship, the Alfried Krupp-Förderpreis für junge Hochschullehrer, research grants from the Deutsche
Forschungsgesellschaft, and by the Fonds der Chemischen Industrie (grants to L. H.).

\section{REFERENCES}

Cho, H., Heide, L. \& Floss, H. G. (1992). Synthesis of D-( -$)-[1,7-$ ${ }^{13} \mathrm{C}_{2}$ ]shikimic acid. J Labelled Compd \& Radiopharm 31, 589-594.

Chou, P. Y. \& Fasman, G. D. (1978). Prediction of the secondary structure of proteins from their amino acid sequence. Adv Envymol 47, 45-148.

Cornish-Bowden, A. (1977). An automatic method for deriving steady-state rate equations. Biochem $J$ 165, 55-59.

Cornish-Bowden, A. \& Eisenthal, R. (1974). Statistical considerations in the estimation of enzyme kinetic parameters by direct linear plot and other methods. Biochem $J$ 139, 721-730.

Cox, G. B. \& Gibson, F. (1966). The role of shikimic acid in the biosynthesis of vitamin $\mathrm{K}_{2}$. Biocbem J 100, 1-6.

Eisenthal, R. \& Cornish-Bowden, A. (1974). The direct linear plot. Biochem J 139, 715-720.

Garnier, J., Osguthorpe, D. J. \& Robson, B. (1978). Analysis of the accuracy and implications of simple methods for predicting the secondary structure of globular proteins. J Mol Biol 120, 97-120.

Gibson, M. I. \& Gibson, F. (1964). Preliminary studies on the isolation and metabolism of an intermediate in aromatic biosynthesis : chorismic acid. Biochem J 90, 248-256.

Gottesman, S., Halpern, E. \& Trisler, P. (1981). Role of $s u l A$ and sulB in filamentation by lon mutants Escherichia coli $\mathrm{K}-12$. J Bacteriol 148, 265-273.

Harzer, K. (1970). Analytische isoelektrische Fraktionierung der $N$ Acetyl- $\beta$-D-hexosaminidasen. $Z$ Anal Chem 252, 170-174.

Laemmli, U. K. (1970). Cleavage of structural proteins during the assembly of the head of bacteriophage T4. Nature 227, 680-685.

Lawrence, J., Cox, G. B. \& Gibson, F. (1974). Biosynthesis of ubiquinone in Escherichia coli K-12: biochemical and genetic characterization of a mutant unable to convert chorismate into 4hydroxybenzoate. J Bacteriol 118, 41-45.

Lesley, S. A., Brow, M. A. \& Burgess, R. R. (1991). Use of in vitro protein synthesis from polymerase chain reaction-generated templates to study interaction of Escherichia coli transcription factors with core RNA polymerase for epitope mapping of monoclonal antibodies. J Biol Chem 266, 2632-2638.

Lisser, S. \& Margalit, H. (1993). Compilation of E. coli mRNA promoter sequences. Nucleic Acids Res 21, 1507-1516.

Nichols, B. P. \& Green, J. M. (1992). Cloning and sequencing of Escherichia coli ubiC and purification of chorismate lyase. $J$ Bacteriol 174, 5309-5316. 
O'Neill, M. C. (1989). Escherichia coli promoters. 1. Consensus as it relates to spacing class, specificity, repeat substructure, and threedimensional organization. J Biol Chem 264, 5522-5530.

Ozenberger, B. A., Brickman, T. J. \& Mclntosh, M. A. (1989). Nucleotide sequence of Escherichia coli isochorismate synthetase gene ent $C$ and evolutionary relationship of isochorismate synthetase and other chorismate-utilizing enzymes. $J$ Bacteriol 171, 775-783.

Parson, W. W. \& Rudney, H. (1965). The biosynthesis of ubiquinone and rhodoquinone from $p$-hydroxybenzoate and $p$ hydroxybenzaldehyde in Rhodospirillum rubrum. J Biol Chem 240, 1855-1863.

Pennock, J. F. \& Threlfall, D. R. (1983). Biosynthesis of ubquinone and related compounds. In Biosynthesis of Isoprenoid Compounds vol. 2, pp. 191-203. Edited by J. Porter \& S. L. Spurgeon. New York: Wiley.

Sambrook, J., Fritsch, E. F. \& Maniatis, T. (1989). Molecular Cloning: a Laboratory Manual. Cold Spring Harbor, NY: Cold Spring Harbor Laboratory.

Short, J. M., Fernandez, J. M., Sorge, J. A. \& Huse, W. (1988). $\lambda$ ZAP: a bacteriophage expression vector with in vivo excision properties. Nucleic Acids Res 16, 7583-7600.

Siebert, M., Bechthold, A., Melzer, M., May, U., Berger, U., Schröder, G., Schroder, J., Severin, K. \& Heide, L. (1992). Ubiquinone biosynthesis: cloning of the genes coding for chorismate pyruvate-lyase and 4-hydroxybenzoate octaprenyl transferase from Escherichia coli. FEBS Lett 307, 347-350.
Stroobant, P., Young, I. G. \& Gibson, F. (1972). Mutants of Eschericbia coli $\mathrm{K}-12$ blocked in the final reaction of ubiquinone biosynthesis: characterization and genetic analysis. J Bacteriol 109, 134-139.

Wallace, B. J. \& Young, I. G. (1977). Role of quinones in electron transport to oxygen and nitrate in Escherichia coli: studies with a ubi $A^{-}$men $A^{-}$double quinone mutant. Biocbim Biopbys Acta 461, 84-100.

Walsh, C. T., Liu, J., Rusnak, F. \& Sakaitani, M. (1990). Molecular studies on enzymes in chorismate metabolism and the enterobactin biosynthetic pathway. Chem Rev 90, 1105-1129.

Young, I. G., Batterham, P. J. \& Gibson, F. (1969). The isolation, identification, and properties of isochorismic acid. An intermediate in the biosynthesis of 2,3-dihydroxybenzoic acid. Biochim Biopbys Acta 177, 389-400.

Young, I. G., Langman, L., Luke, R. K. \& Gibson, F. (1971). Biosynthesis of the iron-transport compound enterochelin : mutants of Eschericbia coli unable to synthesize 2,3-dihydroxybenzoate. $J$ Bacteriol 106, 51-57.

Young, I. G., Leppik, R. A., Hamilton, J. A. \& Gibson, F. (1972). Biochemical and genetic studies on ubiquinone biosynthesis in Escherichia coli K-12: 4-hydroxybenzoate octaprenyltransferase. $J$ Bacteriol 110, 18-25.

Received 13 August 1993; revised 6 October 1993; accepted 26 October 1993. 